\title{
A Natural Attenuation of Heavy Metals in a Stream Contaminated by Acid Mine Drainage from Artisanal Gold Mining in Cambodia
}

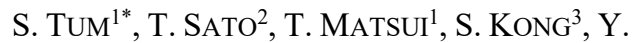 \\ $\mathrm{OHTOMO}^{2}$, R. KIKUCHI ${ }^{2}$, AND T.OTAKE ${ }^{2}$ \\ ${ }^{1}$ Graduate School of Engineering, Hokkaido Univ., 060-8628, \\ Sapporo, Japan \\ (*correspondence: tsroith@eis.hokudai.ac.jp) \\ ${ }^{2}$ Faculty of Engineering, Hokkaido Univ., 060-8628, \\ Sapporo, Japan \\ ${ }^{3}$ Geology Dept., Ministry of Mine and Energy, 12210, \\ Phnom Penh, Cambodia
}

The artisanal miners in Mondulkriri province, Cambodia dumped the sediment and wastewater after gold processing to a small stream which is a tributary to the main river; Prek Te. In the dry season, the stream water was highly polluted. On the other hand, in the rainy season, the heavy metals concentration decreased to less than WHO drinking water standard without any treatment before mixing with the main river. This phenomenon implied an occurrence of natural attenuation in the stream. To understand the natural attenuation behaviors of the stream, detail analyses of water, stream sediment in dry and rainy seasons, and ore were conducted.

The stream water was contaminated due to the gold processing by sulfuric acid that dissolved the ore containing arsenopyrite, pyrite, and pyrolusite as well as the oxidation of pyrite in the waste rock. Mine wastewater $\mathrm{pH}$ is 2.7 while in the stream $\mathrm{pH}$ is 2.8 in the dry season and 3.5 in the rainy season. The heavy metals; Fe, Mn, As, Se concentration in the mine waste are approximately $700 \mathrm{ppm}, 45 \mathrm{ppm}, 15 \mathrm{ppm}$, $0.043 \mathrm{ppm}$ respectively. As and Se concentration reduced from $0.4 \mathrm{ppm}$ and $0.025 \mathrm{ppm}$ (dry season) to $0.005 \mathrm{ppm}$ and $0.002 \mathrm{ppm}$ (rainy season) at sampling site before mixing with Prek Te river. The decrease of As and Se concentration in the rainy season was due to the co-precipitation and adsorption by schwertmannite that precipitated in the stream bed. The natural attenuation significantly occurred when $\mathrm{pH}$ increases to 3.5 due to the presence of schwertmannite colloid aggregation. The main factors controlling natural attenuation were the increase of $\mathrm{pH}$ to 3.5 and dilution in this system as a result of the rainwater and water from its tributaries input to the stream. This study implied the applicable of sustainable passive treatment for the contaminated drainage from the small-scale gold mine by increasing the $\mathrm{pH}$ of the stream to 3.5 and dilution by the non-contaminated river in the dry season. 